\title{
Computer simulations of high shore littorinids predict small-scale spatial and temporal distribution patterns on rocky shores
}

\author{
Richard Stafford ${ }^{1}$, Mark S. Davies ${ }^{2}$, Gray A. Williams ${ }^{1, *}$ \\ ${ }^{1}$ The Swire Institute of Marine Science, Department of Ecology \& Biodiversity, The University of Hong Kong, Cape d'Aguilar, \\ Shek O, Hong Kong, SAR \\ ${ }^{2}$ School of Health, Natural and Social Sciences, University of Sunderland, Sunderland SR1 3SD, UK
}

\begin{abstract}
High shore littorinid snails exhibit complex spatial distribution patterns, forming dense aggregations both in crevices and on crevice-free sections of rocky shores. To understand how these patterns may form, an individual-based computer simulation of littorinid behaviour, similar to those used to model social insects, was used to mimic snail movement on rocky shores. Individual littorinid movement patterns were simulated, along with chance interactions with other littorinids, their trails, crevices and any resultant decisions made by the littorinids when these interactions occurred. The simulation investigated how simple behavioural rules can predict spatial aggregation patterns and the persistence and variation of these aggregation patterns over timescales of several tidal cycles. Morisita's index of dispersal showed good agreement between the simulation and observed patterns of littorinids on-shore. Trail-following was vital in the simulation, since points where trails intersected with crevices, or points where 2 or more trails met, formed the site of aggregations. Both in the simulation and in reality, aggregations often occurred in identical positions over several tidal cycles, both within and outside crevices. This temporal predictability may be due to the persistence of mucus trails on the shore over successive tidal cycles. Removal of the influence of past mucus trails from the simulation resulted in far lower persistence of aggregations over time. The simulation, therefore, is an important tool in examining behavioural mechanisms of intertidal animals. It provides insights into how simple behaviour of grazing animals can explain complex population patterns and subsequently the community dynamics of algal-herbivore interactions.
\end{abstract}

KEY WORDS: Aggregation · Trail following · Mucus trails · Echinolittorina $\cdot$ Computer simulation · Individual-based model · Hong Kong

\section{INTRODUCTION}

Ecological models are frequently mathematical, population-based models, or models that demonstrate topdown control of a population or group of individuals (Taylor \& Jefferson 1994; see examples in Case 2002). However, research into modelling the behaviour of social insects has demonstrated how such behaviour can be modelled using individual-based simulations (Bonabeau et al. 1999; see Grimm \& Railsback 2005 for an introduction to individual-based modelling in ecology). These simulations often model interactions between individuals that result in complex, population level behaviours, as found in the real animals (Nitschke 2005). Such modelling techniques have also been used to create robots with life-like behaviour (Dorigo et al. 2004). Such studies have proved important in understanding the mechanisms that real animals use to interact with their environment because these robots need to be controlled at an individual level and can only use information from their local environment (reviewed by Camazine et al. 2001).

In this study we investigate the behaviour of littorinid snails, which are the dominant fauna high in the intertidal zone on rocky shores worldwide (Stephenson \& Stephenson 1972, Reid 1996). Rocky 
shore animals show relatively simple individual level behaviour, and data on their behavioural patterns are moderately easy to obtain, making them ideal candidates for this type of individual-based model. A key feature of the spatial patterns of littorinids is their highly contagious distribution whilst emersed, with large aggregations of individuals occurring both in crevices and on areas of crevice-free rock (Emson \& Faller-Fritsch 1976, Raffaelli \& Hughes 1978, Garrity 1984, Britton et al. 1991, Chapman 1995, Chapman \& Underwood 1996). These aggregations reduce desiccation stress and the risk of dislodgement of the snails by waves (Raffaelli \& Hughes 1976, Garrity 1984, Chapman \& Underwood 1996).

Even though the time available for foraging is limited, since littorinids mostly forage whilst awash (Little 1989, Williams 1994), these snails influence the growth and abundance of the epilithic biofilm through grazing. On some high shores the spatial influence on the biofilm is very small and localised around aggregations (e.g. north-east England; Stafford \& Davies 2005a) whereas on other shores there appears to be more extensive control of the biofilm (e.g. Hong Kong; Mak \& Williams 1999). Understanding the distribution patterns of the snails throughout their grazing period will allow more accurate understanding of the spatial variation in grazing effort and a better understanding of the effects of the snails on the epilithic biofilm (Stafford et al. 2005).

On the high shore, the degree of aggregation of littorinids appears relatively constant from day to day, unaffected by physical conditions such as temperature and wave action (Stafford 2002, Stafford \& Davies 2004; but see Jones \& Boulding 1999 for contrasting results from lower on the shore). This lack of behavioural plasticity has potential advantages for life on the high shore (Stafford \& Davies 2004) and the predictable distribution patterns indicate that simple behaviours may be key to their production. The methods of aggregation of high shore littorinids are, however, unclear (Chapman 1995, 1998). The snails do not, for example, show homing behaviour. Species of the genus Echinolittorina on shores in Hong Kong have been shown to be displaced by $>2 \mathrm{~m}$ during a single tidal immersion, with the average displacement of an individual exceeding the distance between one aggregation and its nearest neighbour (Stafford 2002). Therefore, little site fidelity over time occurs in individual littorinids.

Recently, Stafford \& Davies (2005b) produced a simulation model of individual littorinid behaviour using data from a European littorinid, Melarharphe neritoides. Movement patterns were investigated in laboratory studies and distribution patterns of up to 40 littorinids were simulated and tested against experimental results obtained under laboratory conditions. The simulation modelled individual movement patterns of each littorinid, along with a time-dependent likelihood of aggregation, crevice occupation and trail-following, conditional on encounters with other individuals, crevices or trails. The simulation accurately predicted distribution patterns found in equivalent laboratory experiments and, as in previous studies on simulation and modelling of aggregation in intertidal molluscs (e.g. Chelazzi et al. 1984, Focardi et al. 1985, 1989) mucus trail-following was found to play an important role.

Despite the success of the model, the results were not consistent with the behaviour or aggregation patterns found on natural high shore areas. This was largely due to the highly constrained movement patterns of this littorinid on natural shores, as the snails forage almost exclusively ( $93 \%$ of the time) in small grazing halos surrounding dense aggregations of individuals (Stafford \& Davies 2005a).

In this study the computer simulation was adapted to investigate patterns of distribution of 2 common species of high shore littorinid-Echinolittorina trochoides (Gray) and E. radiata (Eydoux \& Souleyet) on a natural rocky shore in Hong Kong. These species do not show the same constrained foraging patterns as littorinid snails in north-east England; instead, they move up the shore on the rising tide, forage while awash by the waves, and then move back down the shore with the ebbing tide (Williams 1994). As the tide retreats, the snails stop moving, remaining relatively high on the shore, and they are frequently found in aggregations consisting of both species, either on flat rock, or inside crevices in the rock surface (Williams 1994, Mak 1996).

The purpose of this study was to determine whether simple behavioural rules could account for the complex spatial patterns found on a natural rocky shore. If these rules resulted in small areas of the shore being repeatedly occupied by littorinids over a short temporal scale, this would potentially create an uneven exploitation of resources and produce a patchy distribution of resources. Here, data from a computer simulation of aggregation on virtual shores were used to identify the mechanisms of aggregation, both within and outside crevices. The predications of the computer simulation were tested against further data collected from the shore to highlight the possible mechanisms used by high shore snails for aggregation on the shore.

\section{MATERIALS AND METHODS}

Field observations. Observations were made on moderately exposed rocky shores at Cape d'Aguliar, Hong Kong $\left(22^{\circ} 12^{\prime} \mathrm{N}, 114^{\circ} 15^{\prime} \mathrm{W}\right)$ between 30 April and 
4 May 2006. Small-scale spatial distributions of littorinids were assessed over successive tidal cycles in $1 \mathrm{~m}^{2}$ areas of rocky shore at $>2.25 \mathrm{~m}$ above chart datum. Study sites $\left(1 \mathrm{~m}^{2}\right.$ of rocky shore with littorinids present at the required shore height; $n=5$ ) were identified as close as possible to randomly selected locations. The topography and crevice distribution of the sites are indicated in Fig. 1.

Photoquadrats of each site were taken each day, after the littorinids had stopped moving, following the fall of the tide. This daily sampling captured the spatial distribution of the littorinids after one foraging period as, during the study period, only one high tide per day was of sufficient amplitude to stimulate foraging in the littorinids. Photoquadrats ensured the littorinids were not disturbed or dislodged. Preliminary studies indicated that an exact count of littorinid numbers could be obtained from the photoquadrats for those animals not in crevices (see Fig. 1). For littorinids aggregating inside crevices, results from the photoquadrats were as good as direct inspection of the study sites and reliable estimates of littorinid number in a $50 \times 50 \mathrm{~mm}$ section of shore could be obtained from this method $( \pm 5 \%$; in most cases \pm 1 snail). Exact counts of littorinids were only possible if they were removed from the crevice, defeating one purpose of the present study, which was to investigate spatial patterns over successive tidal cycles.
Photoquadrats were analysed using image analysis software (Image J, National Institutes of Health, USA; available at: http://rsb. info.nih.gov/ij/) by dividing the square metre into 400 squares of $50 \times 50 \mathrm{~mm}$. For Sites 1 $\& 2$, the spatial distribution over the entire square metre was established by randomly sampling 40 of these squares and counting the number of snails present in each. Morisita's index of dispersal was then calculated:

$$
I_{\mathrm{d}}=n\left[\Sigma X^{2}-\Sigma X /(\Sigma X)^{2}-\Sigma x\right]
$$

where $I_{\mathrm{d}}$ is Morisita's index of dispersal, $x$ is the number of littorinids in a quadrat and $n$ is the number of replicate quadrats.

Temporal persistence of aggregations was investigated at the remaining 3 sites (Sites 3 to 5). Six squares per site, each with $>5 \%$ of the total number of littorinids at that site, were selected: 3 squares were in crevices and 3 squares on flat rock. Squares fitting the above criteria were selected at random, unless fewer squares than required contained $>5 \%$ of the total littorinid number, in which case the squares with the greatest number of littorinids present were used. The small rockpools in Sites 4 \& 5 (Fig. 1) were excluded from the area sampled. The same squares were examined after each tidal immersion and the number of littorinids in each was noted, along with the percentage of snails in each square, as compared to the initial

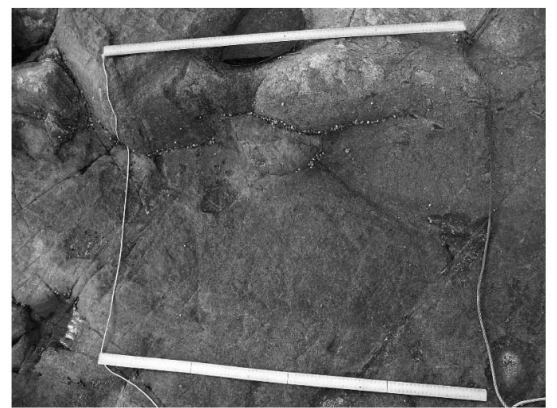

Site 1

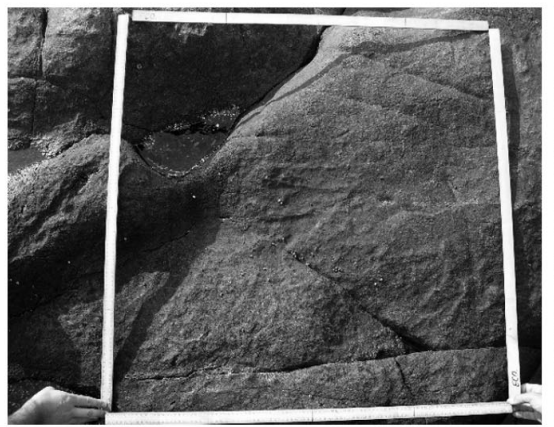

Site 4

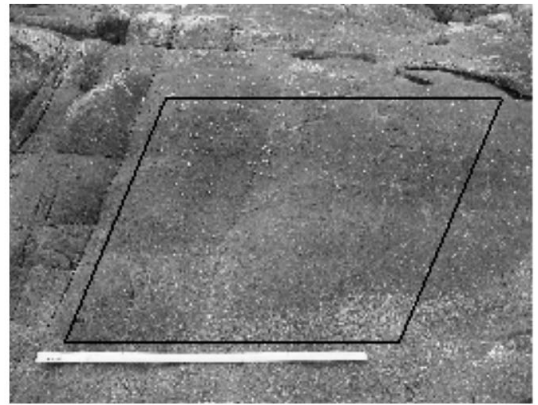

Site 2

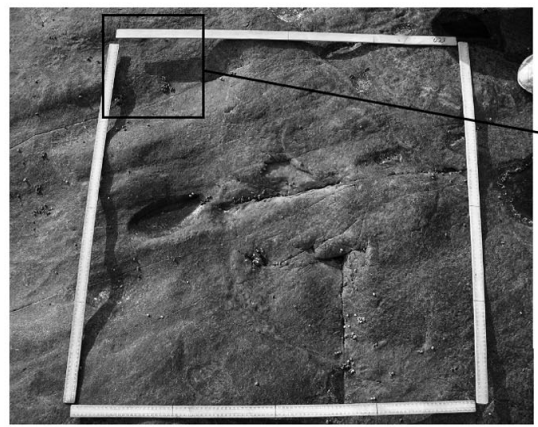

Site 5

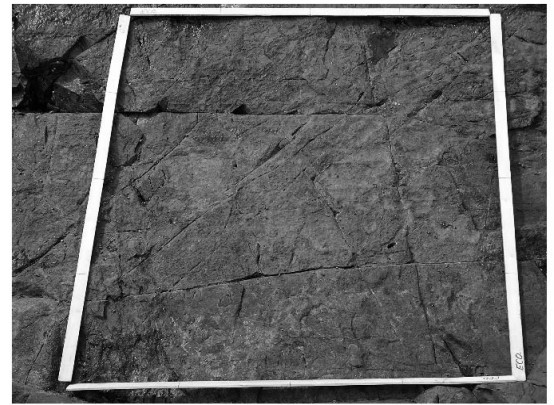

Site 3

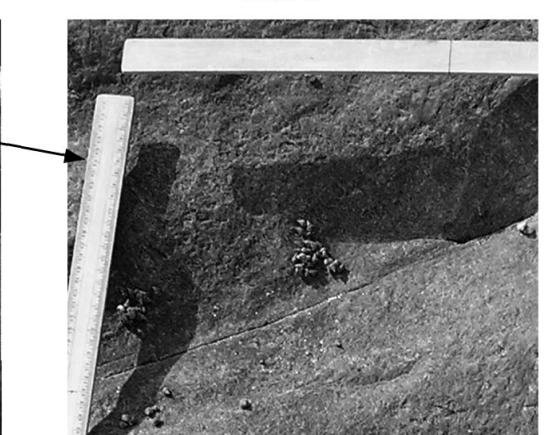

Site 5 Magnified Inset

Fig. 1. Photoquadrats from all 5 sites demonstrating topography and crevice distribution. Photographs taken $3 \mathrm{~d}$ before data collection started to prevent disturbance effects from metre rules. Site 2 shows a single metre rule, as the slope of the shore did not allow a quadrat to be defined in a normal manner without disturbing littorinids. Inset to Site 5 shows magnified section of photoquadrat demonstrating how littorinids can easily be counted from photoquadrats 
number. Five tidal cycles were sampled, Tidal Cycle 1 being the initial sampling day. For Site 3 only 4 tidal cycles (Tidal Cycles 1 to 4 ) could be sampled: on Tidal Cycle 5, snails continued to be awash due to wave exposure and were still moving after dark.

Data collection for parameterising the computer simulation. Data used to simulate movement patterns and decision-based rules were collected as described in Stafford (2002) and Stafford \& Davies (2005b); a brief overview of the methods is given here. All data were collected in the laboratory using observations and image analysis from snails moving on artificial substrata. Movement patterns of individual snails were obtained in isolation from other snails and the artificial substratum cleaned thoroughly between replicate trials to remove mucus trails. Movement patterns of 20 snails of each species (Echinolittorina trochoides and E. radiata) were constructed from image analysis, with data from 10 snails from each species being used to parameterise the movement model, and the movement patterns of the remaining 10 snails being used to test the output of the simulation. Differences in the distance moved, tortuousity of movement and the frequency of various decisions made by the 2 species of snail were shown to be extremely small (Stafford 2002) and, as a result, the simulation did not explicitly separate the 2 species.

Decision-based rules were constructed from observational and image analysis data, collected from between 10 and 40 snails moving on artificial substrata in the laboratory. The number of interactions with crevices and other snails were recorded along with the time since immersion of the snails. The frequency of interactions resulting in crevice occupation or aggregation formation was then calculated. Using image analysis software (OSIRIS, University of Geneva; available at: http://www.sim.hcuge.ch/osiris/) trails of each snail were plotted and trail-following frequency calculated. Snails were always seen to follow trails in the direction they were originally laid, and once they had started trail-following, the snails remained on trails for $>30 \mathrm{~min}$, apart from in the final $5 \mathrm{~min}$ of the $90 \mathrm{~min}$ period.

Computer simulation. The simulated $1 \mathrm{~m}^{2}$ rocky shore was divided into a grid of $5 \times 5 \mathrm{~mm}$ squares. Snails could move from 1 square to any of the 8 neighbouring squares, giving an average distance between squares of $\sim 6 \mathrm{~mm}$, the length of an average snail. One timestep in the simulation was defined as the time taken for each snail to move from one grid square to a neighbouring grid square. The simulation lasted 400 timesteps and simulated snails moved distances similar to real snails during a tidal cycle, i.e. 1 to $2 \mathrm{~m}$.

For the first simulations, 200 snails were initially located randomly in the lower 100 rows of the grid. For simulations which explicitly test the simulation output against field data, the density of snails in the simulation was set to be the same as the density of snails in the field. These snails were again randomly located in the lower 100 rows of the grid. The simulation began at the time that the snails would be washed by the rising tide, and each individual moved up the shore with an initial bearing of $0^{\circ}$. At each timestep a new bearing was obtained by summing the previous bearing with a randomly generated angle from a normal distribution (mean $\left.=0^{\circ}, \mathrm{SD}=10^{\circ}\right)$. A bearing of $0^{\circ}$ was also applied at Timesteps $10,20,40 \& 80$ to maintain an overall upshore direction. Once in the top 40 rows of the grid (the position at high tide) the randomly generated angle was changed to give a more tortuous movement pattern (mean $=0^{\circ}, \mathrm{SD}=100^{\circ}$ ) indicating foraging in the awash zone. As the tide ebbed, and snails would start to move down the shore, simulated snails were initially given a bearing of $180^{\circ}$, and then the bearing was again modified by a random angle (mean $=0^{\circ}, \mathrm{SD}=10^{\circ}$ ) at each timestep. These bearings and angles were based on the parameters obtained and tested in laboratory studies and mimicked real snail behaviour as they moved up and down the shore with the rise and fall of the tide.

Snails were prevented from moving off the top of the simulated shore by restricting upward movement directions. Thus snails could only move horizontally or downward at that edge. In a typical simulation this only affected $\sim 5 \%$ of all simulated snails, and in reality few snails forage or move above the main awash zone on the shore. Snails moving off the side of the simulated shore rejoined on the opposite side, moving in the same direction. Snails were able to leave the bottom of the simulated shore, and if they did so in the final tidal cycle of the simulation, were not included in further analysis. Snails leaving the bottom of the shore in simulations of more than one tidal cycle rejoined the simulation at the bottom of the grid at the start of the next tidal simulation, with their horizontal positions being randomly determined.

At each timestep, each snail deposited mucus onto the virtual shore. If an individual entered a mucus free $5 \times 5 \mathrm{~mm}$ grid square, one unit of mucus was deposited onto it. If the grid square contained mucus from an earlier snail of a value of one unit or more, then only 0.5 units of mucus were deposited, as trail-following snails deposit ca. half the amount of mucus of trail laying snails: single trails of Littorina littorea are ca. $35 \mu \mathrm{m}$ thick, double trails are ca. $47 \mu \mathrm{m}$ thick at the centre of the trail (Davies \& Blackwell 2007). The simulated mucus also contained directional information, indicating the direction in which it was laid. Snails only followed trails in the direction they were laid, as indicated by laboratory studies (see above).

Three behavioural rules were incorporated into the model: an aggregation rule, where decisions were 
made when snails encountered other snails; a crevice occupation rule, where decisions were made when snails encountered a crevice; and a trail-following rule, where decisions were made when a snail encountered the trail of another snail, or its own trail. To simulate a decision, a random number between 0 and 1 was compared to the sigmoidal probability threshold $y$, which increased with the time of the simulation:

$$
y=1 /\left(1+\mathrm{e}^{-a(t-b)}\right)
$$

where $t$ is the timestep (between 1 and 400). For the crevice occupation rule $a=0.07, b=290$; the aggregation rule $a=0.07, b=360$; and the trail-following rule $a=0.09, b=290$. Parameters were obtained by fitting the above equation to data from naturally moving snails in laboratory studies (see Appendix 1 for sensitivity analysis of simulation parameters and decision rules). If the random number was lower than $y$ then the snails aggregated and stopped moving, occupied crevices and stopped, or followed mucus trails (positive decisions). If the number was higher than $y$ then the snail continued to move as normal. Repeat decisions occurring between snails and the same crevice, the same trail or the same snails were prevented for 10 timesteps. Since the data we collected for parameterisation could not predict the exact time of a decision once an encounter occurred, this was a necessary procedure to prevent too many positive decisions being made. The use of 10 timesteps was based on analysis of how long snails would move along identical paths from the point of first encounter, with $<5 \%$ of snails still being on an identical path as the encountered snail, trail or crevice after 10 timesteps when moving with an angle modified by $\mathrm{SD}=10$ at each timestep. This compares with $\sim 24 \%$ of snails being on identical paths after 5 timesteps, which would result in a large number of 'false positive' decisions without manipulation of the decision parameters. Although aggregated and crevice-occupying snails were not moving, they could take part in further aggregation decisions if other snails encountered them.

The simulation was run for between one and 6 tidal cycles to allow comparison with field data. After the first tidal cycle, and for all subsequent tidal cycles, the spatial distribution of snails was analysed. After each tidal cycle decay of mucus trails occurred. This decay was based on data for Littorina littorea (Davies \& Blackwell 2007). The decay was modelled as:

$$
M_{t+1}=M_{t} \mathrm{e}^{-0.78}
$$

where $M$ is the amount of mucus present at time $t$. Since the above equation results in the indefinite persistence of small traces of mucus, values below 1 unit of mucus in a grid square were removed from the simulation.
Data from computer simulations were either collected using simulated densities of 200 snails $\mathrm{m}^{-2}$ and a distribution of long thin crevices (as shown in Fig. 2a) or with no crevices present (Fig. 2d). When compared with real shore data, the density of snails was set to be identical to that found on the shore at Tidal Cycle 1, and the positions of crevices were identical to those on the shore. Rockpools were simulated as flat rock, but no data were collected from these areas.

Data analysis and statistics. Comparisons of Morisita's index of dispersal (MI) between field data and computer simulated data were conducted using nonparametric tests (Wilcoxon rank sum test). A mean value of $\mathrm{MI}$ considered to be the true mean ( $\mathrm{SE}<0.5 \%$ of mean value) was calculated for the simulation from 500 runs of the simulation. This mean value was tested against the MI values from the field data.

Temporal persistence of aggregations from both real and simulated shores were compared with ANOVA, the independent variable being the percentage of snails in selected $50 \times 50 \mathrm{~mm}$ squares as compared to the number of snails present in the same squares at Tidal Cycle 1. Comparisons between simulations and field data were made in a similar manner to above. A total of 500 runs of the simulation was used to calculate an approximate true mean value for each habitat, site and time combination ( $\mathrm{SE}<0.5 \%$ of mean value); these true means were tested against the field data. The ANOVA model involved 3 factors: the real data were tested against the modelled data (Simulation - a fixed factor with 2 levels) accounting for the fact that data were collected from crevices and flat rock (Habitat - a fixed factor with 2 levels) and from 3 sites (Site a random factor with 3 levels, nested within the interaction of Simulation $\times$ Habitat) for both the simulation and the field data. In both the simulation and the real data each site had 5 replicate samples (squares), where the percentage of snails present, relative to Tidal Cycle 1 , was calculated. In order to accommodate the fact that only 2 of the 3 sites could be sampled at Tidal Cycle 5, and also to avoid repeated measure issues arising from sampling of the same site over successive time periods, 4 different tests were performed to compare Tidal Cycles 2, 3, 4 \& 5 to Tidal Cycle 1.

\section{RESULTS}

\section{Output of the computer simulation}

The computer simulation was initially run with 200 snails moving on $1 \mathrm{~m}^{2}$ of simulated shore over a single tidal cycle. Two simulated shores were analysed, a shore with long thin crevices running horizontally along it, and one with no crevices. The spatial distribu- 


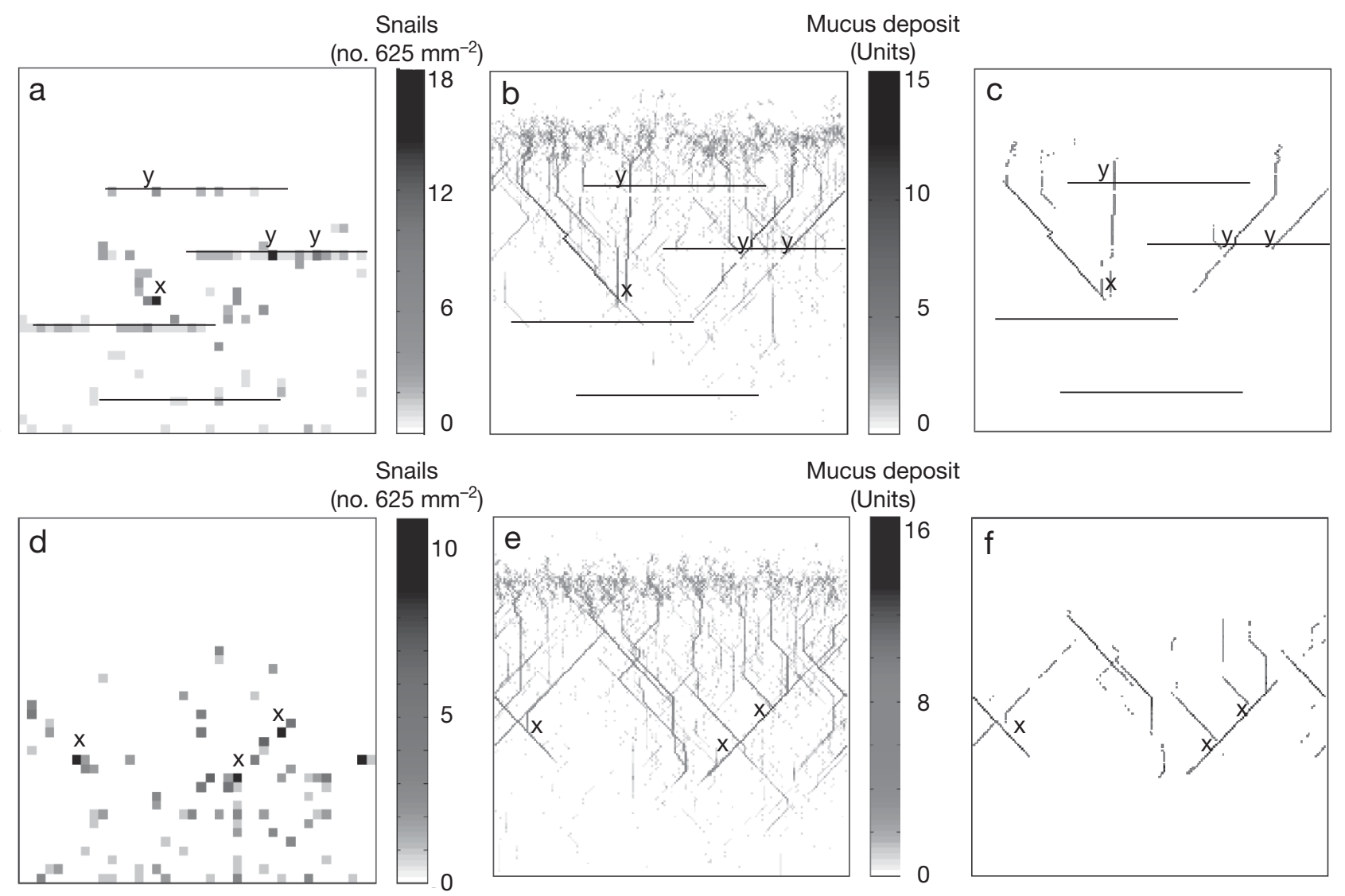

Fig. 2. Aggregation behaviour simulated in intertidal littorinids. (a) Distribution of 200 simulated snails. Snail number grouped into simulated $25 \times 25 \mathrm{~mm}$ quadrats at overall resolution of $40 \times 40$ quadrats. Number of snails in a $25 \times 25$ mm quadrat indicated by shade bar. ' $x$ ': aggregation on flat rock; ' $y$ ': aggregation in a crevice. Thin black lines indicate position of crevices. (b) Trailfollowing on the shore simulated in (a). Shade bar indicates amount of mucus deposited in simulated units. ' $x$ ': aggregations on flat rock, which occur because trails intersect and increase the probability of encounters between individuals; ' $y$ ': indicates aggregation in a crevice, occurring where a heavily used trail intersects with the crevice. ' $x$ ' and ' $y$ ' correspond to positions marked in (a). (c) Trails with $\geq 4$ units of mucus. Intersections of these trails with crevices or with other major trails are often the site of aggregations. $(\mathrm{d}-\mathrm{f})$ same as $(\mathrm{a}-\mathrm{c})$ but for a simulated shore with no crevices present

tion patterns obtained demonstrated many similarities to the distribution of real snails on rocky shores. Dense aggregations of up to 18 snails were found and aggregations occurred both in crevices and on crevice-free sections of shore (Fig. 2a,d). Plots of the degree of trailfollowing down the shore demonstrate how the aggregations formed in the simulation (Fig. 2b,c,e,f). Aggregations formed in crevices (marked as ' $y$ ' on Fig. 2a-c) because many snails moved down the shore on the same trail. If the trail intersected with a crevice, then, depending on how long the simulation had been running, the snails may 'choose' to stop moving in the crevice, either initially through the crevice occupation rule, or subsequently through either the crevice occupation rule or through the aggregation rule.

Aggregations on flat rock were also promoted by trail-following. In this case, places where 2 or more trails intersected often became the location of aggrega- tions. The intersection of trails greatly increases the encounter rate of individual snails, and once 2 or more snails are aggregated at an intersection of trails, other snails moving on those trails will encounter the aggregation once they reach the intersection point (marked as ' $x$ ' in Fig. 2).

Trail-following was vital in establishing dense aggregations. Removal of the trail-following rule from the simulation resulted in large numbers of snails still occurring in crevices, but not in the dense aggregations found previously (Fig. 3a). In the examples shown, the maximum number of individuals in an aggregation was only one third that found when trailfollowing was incorporated, with a maximum of 6 snails in a square as opposed to 18 when trail-following was included. Some small aggregations occurred on flat rock, but they were much smaller than when trailfollowing was included in the simulation (Fig. 3b). 

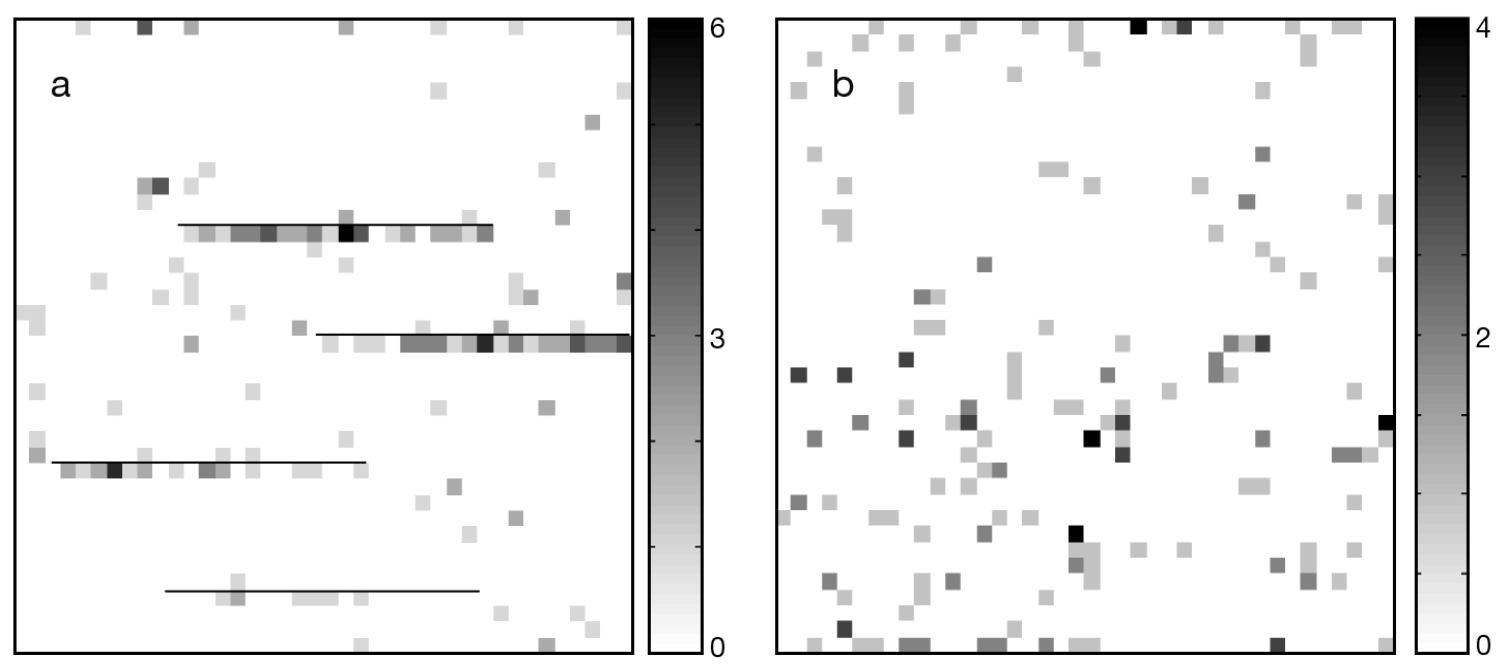

Fig. 3. (a) Simulation identical to that in Fig. 2a, but with trail-following removed from the simulation. Aggregations still occur in crevices, but are much less dense than with trail-following present, as are aggregations on flat rock. (b) as for (a) but for a shore with no crevices

\section{Comparisons of the spatial distribution patterns of littorinids on real and simulated shores}

Two of the selected natural sites (Sites 1 \& 2, Fig. 1), were used to compare the distribution of littorinids on real shores to those obtained from the computer simulation (Fig. 4). Morisita's index of dispersal (MI) did not differ significantly between real and simulated shores (Wilcoxon rank sum test statistic for Site 1 [with crevices] $=30, \mathrm{p}=0.683$ and for Site 2 [no crevices] $=$ $35, \mathrm{p}>0.127$ ).

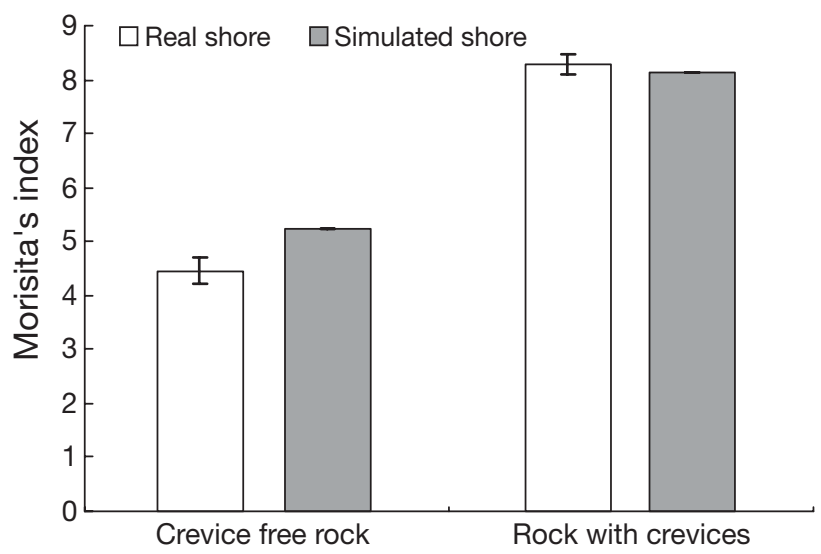

Fig. 4. Comparison of distribution patterns obtained from real and simulated shores. Mean value $( \pm S E, n=5)$ of Morisita's index of dispersal for snail distributions from a section of real shore with long thin crevices (Site 1) and a section of shore with no crevices (Site 2) is compared with the mean from the computer simulation on comparable sections of simulated shore

\section{Comparison of persistence of aggregation locations between real and simulated shores}

Data collected from Sites 3 to 5 were used to investigate the temporal persistence of aggregations over successive tidal cycles. On average, the number of littorinids in a $50 \times 50 \mathrm{~mm}$ square at Tidal Cycle 5 was $\sim 60 \%$ of that found in the same square at Tidal Cycle 1 (Fig. 5), although the individual littorinids occupying the aggregations may be different at each tidal cycle. The real snails were observed to leave these locations to forage during immersion, and so had not stayed in the same position throughout the survey period. Previous results regarding displacement of snails over tidal cycles confirm it was highly unlikely that the persistent aggregations were made up of the same individuals (Stafford 2002), but no attempt was made to investigate this phenomenon.

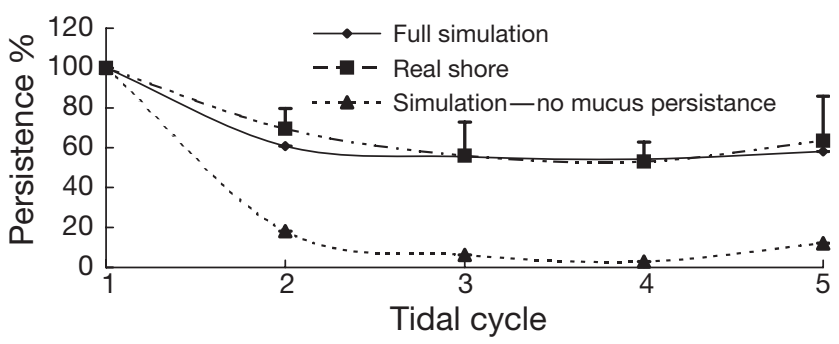

Fig. 5. Mean $(+\mathrm{SE}, \mathrm{n}=18$ or $\mathrm{n}=12$ at Tidal Cycle 5) percentage persistence of littorinids in a small spatial area $(50 \times$ $50 \mathrm{~mm}$ ) over successive tidal cycles. Field data are compared with full simulation and simulation where mucus trail persistence is removed from the model. SE not shown for simulated data ( $\mathrm{SE}<0.5 \%$ of mean) 
Table 1. ANOVA to compare real and simulated shores. Simulation: differences between real and simulated data; Habitat: differences between flat rock and crevices; Site: differences between replicate sites. Data passed Levene's test for homogeneity of variance ( $p>0.05)$. ${ }^{*}: p<0.05$

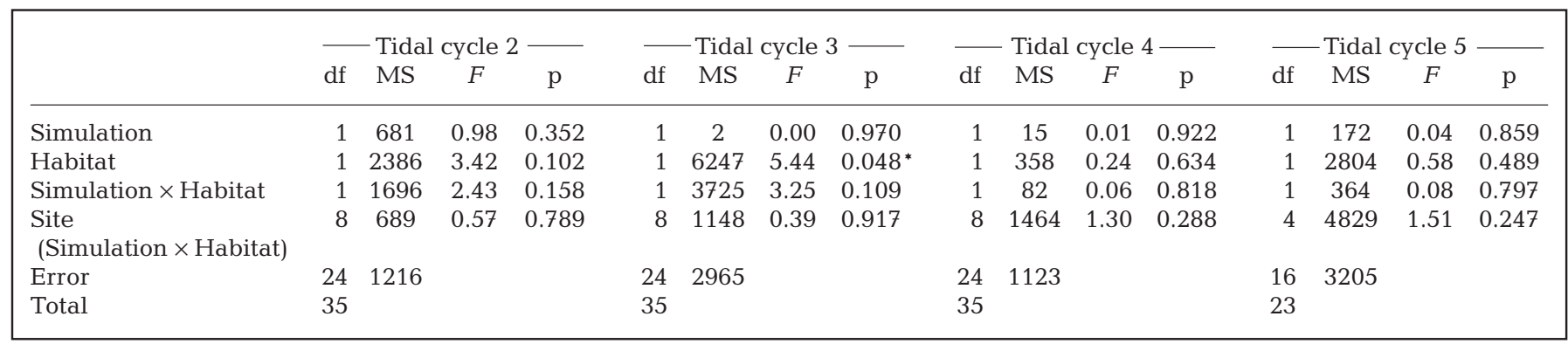

Removal of the persistence of mucus trails from the simulation resulted in a large decrease in the smallscale persistence of aggregations over tidal cycles (Fig. 5). This means that the distribution of snails in similar positions after each tidal cycle is not simply a chance phenomenon.

No significant differences were found in the temporal persistence of aggregations between simulated shores (including persistence of mucus trails) and real shores (Table 1). Furthermore, only the comparison between Tidal Cycles 1 \& 3 showed significant differences with regard to persistence between different habitats, i.e. in crevices and on flat rock (Table 1). Even so, the mean value of persistence of an aggregation in a $50 \times 50 \mathrm{~mm}$ square was larger in crevices (68.3\% for real data, $59.6 \%$ for simulated data) as compared to flat rock $(47.5 \%$ for real data, $52.8 \%$ for simulated data). These differences in means between crevices and flat rock are greater than those between simulation and real shore data $(57.8 \%$ and $56.2 \%$ respectively, Fig. 5).

Despite an initial decrease in the number of snails aggregating in the same location between tidal cycles 1 and 2 (which is likely to partly be a result of the methods of data analysis as Tidal Cycle 1 automatically has a value of $100 \%$ ), no further decrease was apparent over time indicating the persistence of aggregations did not appear to be time dependent within the temporal range studied (Fig. 5).

\section{DISCUSSION}

In this paper we have presented a computer simulation that pre-programs the individual level foraging behaviour of high shore littorinid snails. We provide basic decision rules, which are based on locally available information to the snail, similar to many simulations of social insects (reviewed by Chowbury et al. 2004, Nitschke 2005). Using the computer simulation, parameterised with data collected in the laboratory, we have demonstrated that the small scale spatial and temporal distribution of the snails during emersion can be predicted well.

This study clearly demonstrates the importance of mucus trails and trail-following for aggregation behaviour of littorinid snails. Trail-following has previously been proposed as a mechanism for aggregation in high shore littorinid snails, but evidence from experimental techniques has been relatively inconclusive (Chapman 1998). Simulation and modelling techniques have previously demonstrated the importance of trail-following in gastropods lower on the shore (Chelazzi et al. 1984) and for high shore littorinids in laboratory conditions (Stafford \& Davies 2005b).

The fit of the simulation to real shore data implies that the snails use only the 3 simulated behaviours of aggregation through chance encounter with other snails, crevice occupation through chance encounter with crevices, and trail-following through chance encounter with other trails to establish their spatial locations when emersed. Without carefully controlled manipulative experiments, which would involve an area of shore without any previous mucus trails, it is not possible to confirm this is the case. All the simulated behaviours can, however, be seen to occur in natural populations of Echinolittorina spp. on shores in Hong Kong and in laboratory conditions (Stafford 2002, R. Stafford pers. obs.). It therefore seems reasonable to conclude that the 3 behavioural rules simulated are all likely to be important in dictating the spatial and temporal patterns of high shore snails on the shore. The simulation does not test if any other factors may be important in aggregation formation on the shore, for example, vision, which has previously been considered important in aggregation behaviour (Tankersley 1990). Our simulation does show, however, that the 3 behavioural rules simulated will account for the spatial and temporal distribution of the studied species, without the inclusion of other behavioural rules such as responses to visual cues. Incorporating aspects such as vision into the simulation would be problematic, largely due to the difficulty in obtaining suitable parameters from observations of the snails. 
Although it has previously been difficult to demonstrate the role of factors such as trail-following in the formation of aggregations through experimental techniques (e.g. Chapman 1998), combining the predictions of this simulation with suitable manipulative experiments may allow the assumptions of the simulation to be investigated, along with the roles of other possible behavioural traits which may influence the distribution of the snails, for example visual cues.

A weakness of the present study is that the individual-level foraging behaviour of each snail is pre-programmed into the simulation. Although these behaviours are modified by interactions with other snails and the environment, resulting in the spatial distribution of many individuals arising as an emergent property of the model, it does not explain the fundamental drivers of foraging behaviour. The rhythmic up and down movement of the snails with the tide is likely to be caused by hydrotaxis (Britton et al. 1991), but other factors, such as topographic complexity or food availability, might influence these individual-level movement patterns and ultimately affect the distribution patterns.

Despite these weaknesses, the computer simulation accurately predicts real shore patterns in space and time, and as such can be useful in further ecological research (Stafford et al. 2005). Although this is one of the first simulation models to be applied to rocky shore communities, it is highly likely that the behaviour of other rocky shore gastropod species can be simulated using similar techniques. The techniques of individualbased modelling have been applied to many other species of animal, for example cooperative behaviour in insects, flocks of birds, shoals of fish and even phenomena arising from human behaviour such as traffic jams (Resnick 1997, Sumpter 2006). Many cooperative interactions, for example those in ants and termites, have demonstrated the importance of trail-following (reviewed by Bonabeau et al. 1997), which is also a common behaviour in intertidal gastropods (reviewed by Davies \& Hawkins 1998).

The persistent patchy distribution of snails over several tidal cycles may result in an uneven exploitation of resources, especially of the epilithic biofilm, as a result of concentration of foraging paths. The emersed patterns of the snails do not show an ideal free distribution with respect to food supply, since the snails move down the shore, away from their foraging location. However, aggregation can be a predicted outcome of the ideal free distribution (Sutherland 1983). It is possible that the spatial distribution of the snails does follow the ideal free distribution when factors such as proximity of food, crevice abundance and the increased desiccation stress of living higher on the shore are combined.
Since different individuals make up the aggregations during each tidal cycle, these snails do not strictly demonstrate central place foraging (Orians \& Pearson 1979). However, aggregations persist over time in the same locations and some depletion of local biofilm around the aggregation points may occur. Since the snails move to a foraging area in the awash zone, however, any local depletion of food is unlikely to be at the same scale as the grazing halos associated with Melarhaphe neritoides (Hawkins \& Hartnoll 1983, Stafford \& Davies 2005a) or predation halos associated with dogwhelks on European shores (Burrows \& Hughes 1989, Johnson et al. 1998).

This study demonstrates that simple, individualbased behaviour can determine behaviour at a group level and may have effects at the community level. Using accurately parameterised simulation models of grazers, similar to the model presented in this paper, combined with models of biofilm growth and recruitment, we can begin to explore and predict how individual behaviour can influence the dynamics of grazerproducer interactions.

Acknowledgements. We are grateful to the Agriculture, Fisheries and Conservation Department, HKSAR Government for permission to work in the Cape d'Aguilar Marine Reserve.

\section{LITERATURE CITED}

Bonabeau E, Theraulaz G, Deneubourg JL, Aron S, Camazine S (1997) Self-organization in social insects. Trends Ecol Evol 12:188-193

Bonabeau E, Dorigo M, Theraulaz G (1999) Swarm intelligence: from natural to artificial systems. Oxford University Press, Oxford

Britton JC, McMahon RF, Hart JW (1991) Relationships between topography, substratum composition and surface temperature, and the spatial distribution of intertidal fauna on rocky shores of south-western Australia. In: Wells FE, Walker DI, Kirkman H, Letherbridge R (eds) The marine flora and fauna of Albany, Western Australia. Western Australian Museum, Perth, p 521-540

Burrows MT, Hughes RN (1989) Natural foraging of the dogwhelk, Nucella lapillus (Linnaeus): the weather and whether to feed. J Molluscan Stud 55:285-295

Camazine S, Deneubourg JL, Franks NR, Sneyd J, Theraula G, Bonabeau E (2001) Self-organization in biological systems. Princeton University Press, Princeton, NJ

Case TJ (2000) An illustrated guide to theoretical ecology. Oxford University Press, Oxford

Chapman MG (1995) Aggregation of the littorinid snail Littorina unifasciata in New South Wales, Australia. Mar Ecol Prog Ser 126:191-202

Chapman MG (1998) Variability in trail-following and aggregation in Nodilittorina unifasciata Gray. J Exp Mar Biol Ecol 224:49-71

Chapman MG, Underwood AJ (1996) Influences of tidal conditions, temperature and desiccation on patterns of aggregation of the high-shore periwinkle Littorina unifasciata in New South Wales, Australia. J Exp Mar Biol Ecol 196: 213-237 
Chelazzi G, Deneubourg JL, Focardi S (1984) Cooperative interactions and environmental control in the intertidal clustering of Nerita textilis (Gastropoda; Prosobranchia). Behavior 90:151-166

Chowbury D, Nishinari K, Schadschneider A (2004) Selforganized patterns and traffic flow in colonies of organisms: from bacteria and social insects to vertebrates. Phase Transitions 77:601-624

Davies MS, Blackwell J (2007) Energy saving through trail following in a marine snail. Proc Soc Ser B 274:1233-1236

Davies MS, Hawkins SJ (1998) Mucus from marine molluscs. Adv Mar Biol 34:1-71

Dorigo M, Tuci E, Gross R, Trianni V and 8 others (2004) The SWARM-BOTS project. Lect Notes Comput Sci 3342:31-44

Emson RH, Faller-Fritsch RJ (1976) An experimental investigation into the effect of crevice availability on abundance and size structure in a population of Littorina rudis: Gastropoda; Prosobranchia. J Exp Mar Biol Ecol 23:285-297

Focardi S, Deneubourg JL, Chelazzi G (1985) How shore morphology and orientation mechanisms can affect the spatial organization of intertidal molluscs. J Theor Biol 112: 771-782

Focardi S, Deneubourg JL, Chelazzi G (1989) Theoretical analysis of rhythmical clustering in an intertidal gastropod. Ecol Model 44:177-194

Garrity SD (1984) Some adaptations of gastropods to physical stress on a tropical rocky shore. Ecology 65:559-574

Grimm V, Railsbeck SF (2005) Individual-based modelling and ecology. Princeton University Press, NJ

Hawkins SJ, Hartnoll RG (1983) Grazing of intertidal algae by marine invertebrates. Oceanogr Mar Biol 21:195-285

Johnson MP, Hughes RN, Burrows MT, Hawkins SJ (1998) Beyond the predation halo: Small scale gradients in barnacle populations affected by the relative refuge value of crevices. J Exp Mar Biol Ecol 231:163-170

Jones KMM, Boulding EG (1999) State dependent habitat selection by an intertidal snail: the cost of selecting a physically stressful microhabitat. J Exp Mar Biol Ecol 242: 149-177

Little C (1989) Factors governing patterns of foraging activity in littoral marine herbivorous molluscs. J Molluscan Stud 55:273-284

Mak YM (1996) The ecology of the high-zoned littorinids Nodilittorina trochoides, N. radiata and N. vidua on rocky shores in Hong Kong. PhD thesis, University of Hong Kong

Mak YM, Williams GA (1999) Littorinids control high intertidal biofilm abundance on tropical Hong Kong rocky shores. J Exp Mar Biol Ecol 223:81-94
Nitschke G (2005) Emergence of cooperation: state of the art. Artif Life 11:367-396

Orians GH, Pearson NE (1979) On the theory of central place foraging. In Horn DJ, Mitchell RD, Stairse GR (eds) Analysis of ecological systems. Ohio University Press, Columbus, OH, p 155-177

Raffaelli DG, Hughes RN (1978) The effects of crevice size and availability on populations of Littorina rudis and Littorina neritoides. J Anim Ecol 47:71-83

Reid DG (1996) Systematics and evolution of Littorina. The Ray Society, London

Resnick M (1997) Turtles, termites, and traffic jams: explorations in massively parallel microworlds. MIT Press, Cambridge, MA

Stafford R (2002) The role of environmental stress and physical and biological interactions on the ecology of high shore littorinids in a temperate and a tropical region. $\mathrm{PhD}$ thesis, University of Sunderland

Stafford R, Davies MS (2004) Temperature and desiccation do not affect aggregation behaviour in high shore littorinids in north-east England. J Negative Results Ecol Evol Bio 1: $16-20$

Stafford R, Davies MS (2005a) Spatial patchiness of epilithic biofilm caused by refuge-inhabiting high shore gastropods. Hydrobiologia 545:279-287

Stafford R, Davies MS (2005b) Examining refuge location mechanisms in intertidal snails using artificial life simulation techniques. Lect Notes Artif Intellig 3630:520-529

Stafford R, Davies MS, Williams GA (2005) Creating an artificial rocky shore ecosystem. Artif Intellig Simul Behav Q 122:5

Stevenson TA, Stevenson A (1972) Life between tidemarks on rocky shores. WH Freeman, New York, NY

Sumpter DJT (2006) The principles of collective animal behaviour. Philos Trans R Soc B 361:5-22

Sutherland WJ (1983) Aggregation and the ideal free distribution. J Anim Ecol 52:821-828

Tankersley RA (1990) Trail-following in Littorina irrorata: the influence of visual stimuli and the possible role of tracking in orientation. Veliger 33:116-123

Taylor C, Jefferson D (1994) Artificial life as a tool for biological inquiry. Artif Life 1:1-13

Williams GA (1994) Grazing by high-shore littorinids on a moderately exposed tropical rocky shore. In: Morton B (ed) The malacofauna of Hong Kong and southern China. III. Proc 3rd Intl Workshop on the malacofauna of Hong Kong and southern China, Hong Kong University Press, p 379-389 
Appendix. Sensitivity analysis

Most of the parameters for the computer simulation were obtained from laboratory studies; those which were not, particularly the parameters regarding mucus deposition and decay, were obtained from laboratory and field data from a related species (Littorina littorea). To account for potential problems in applying the parameters from laboratory studies or different species to our field simulation we have performed a sensitivity analysis of all of the parameters. The parameters of mucus deposition, mucus decay and for the equations relating to the 3 decision-rule probabilities, have been systematically adjusted to both 90 and $110 \%$ of their original values (Table A1). In addition, the position of crevices has been adjusted by moving the long thin crevices from Fig. 2 to new positions, whereby the top 2 crevices have moved $10 \%$ further down the shore and the bottom 2 crevices moved $10 \%$ further up the shore from the top and bottom of the simulated area. The baseline study used to compare the results is an identical simulated section of shore to that shown in Fig. 2, with 200 snails and run over 2 tidal cycles. Morisita's index of dispersal (MI) is calculated as described in the 'Materials and methods' section.

The results show that the simulation is reasonably robust to small changes in the parameter values (Table A1). Changes of $10 \%$ in parameter values all result in $<10 \%$ change in the mean value of MI as compared to the baseline mean.
Table A1. Sensitivity analysis for simulation with adjustment of parameters to 90 and $110 \%$ of original values. Values given are mean values of Morisita's index of dispersal calculated from 500 runs of the simulation, to give good estimates of true mean. Percentage change from baseline mean value is also given

\begin{tabular}{|lrc|}
\hline & $\begin{array}{r}\text { True } \\
\text { mean }\end{array}$ & $\begin{array}{c}\text { \% Change } \\
\text { from baseline }\end{array}$ \\
\hline Baseline & 9.65 & - \\
Crevice position altered & 9.54 & -1.14 \\
$\times 1.1$ mucus deposit & 10.49 & 8.70 \\
$\times 0.9$ mucus deposit & 8.71 & -9.74 \\
$\times 1.1$ crevice decision & 10.30 & 6.74 \\
$\times 0.9$ crevice decision & 8.80 & -8.81 \\
$\times 1.1$ aggregation decision & 9.12 & -5.49 \\
$\times 0.9$ aggregation decision & 9.89 & 2.49 \\
$\times 0.9$ trail-following decision & 9.12 & -5.49 \\
$\times 1.1$ trail-following decision & 9.67 & 0.21 \\
$\times 0.9$ mucus decay & 9.64 & -0.11 \\
$\times 1.1$ mucus decay & 9.36 & -3.01 \\
\hline
\end{tabular}

Submitted: November 4, 2006; Accepted: January 2, 2007 Proofs received from author(s): July 6, 2007
Editorial responsibility: Roger Hughes (Contributing Editor) Bangor, UK 